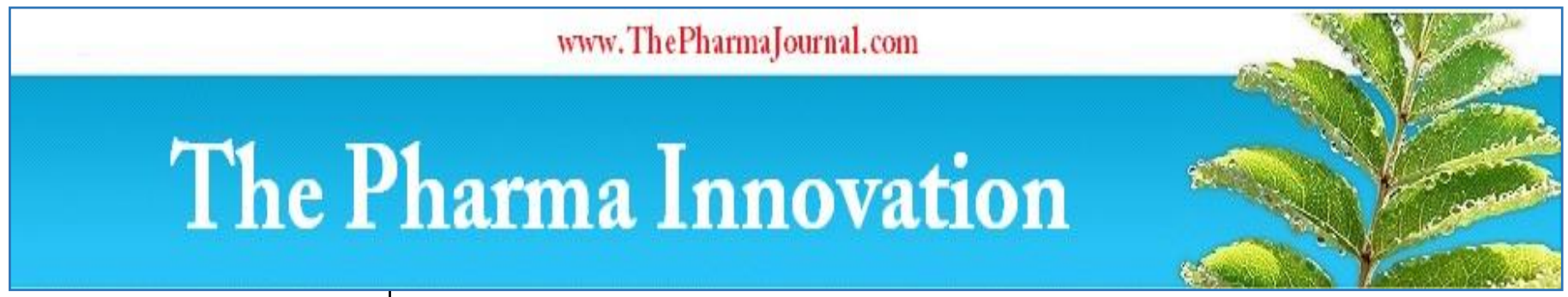

ISSN (E): 2277- 7695

ISSN (P): 2349-8242

NAAS Rating: $\mathbf{5 . 0 3}$

TPI 2020; 9(2): 346-347

(C) 2020 TPI

www.thepharmajournal.com

Received: 04-12-2019

Accepted: 06-01-2020

Deepak

Veterinary Surgeon, Department

of Animal Husbandry and

Dairying, Haryana, India

Dinesh Gulia

Veterinary Surgeon, Department

of Animal Husbandry and

Dairying, Haryana, India

Jitender Yadav

$\mathrm{PhD}$ scholar, National Institute

of Immunology, New Delhi,

India

Siddharth Deswal

Veterinary Surgeon, Department

of Animal Husbandry and

Dairying, Haryana, India

Jagat Singh Kadian

Veterinary Surgeon, Department

of Animal Husbandry and

Dairying, Haryana, India

\section{Medicinal management of Strongyloidiasis in murrah calves}

\section{Deepak, Dinesh Gulia, Jitender Yadav, Siddharth Deswal and Jagat Singh Kadian}

DOI: https://doi.org/10.22271/tpi.2020.v9.i2g.4396

Abstract

Livestock plays an important role in Indian rural economy and is a prime agricultural subsector. Endoparasites infections in domestic animals cause huge economical losses to the farmers. Nematodes like Strongyloides spp. are obligate gastrointestinal parasites of vertebrates. The larvated eggs of the Strongyloides spp. are expelled in the faeces of the host animals. The current study describes the clinical signs, diagnosis via microscopic faecal examination and medicinal management of Strogyloides spp. infection in Murrah calves. The infected calves were successfully treated with Piperazine and Levamisole.

Keywords: Strogyloides, piperazine, levamisole, murrah, infection, calves

\section{Introduction}

Murrah buffalo is an important integrant of the profitable dairy industry of Haryana state of India. Endoparasitic infections are one of the main hindrance in the profit earning dairy industry of the developing countries including India. Along with the infected animals, helminths also adversely affect the human populations rearing these animals. Endoparasites cause huge economical losses to the dairy farms as they are responsible for digestive problems, reduction in production, reduction in weight gain, poor reproductive performance and mortality in the infected animals ${ }^{[1]}$. Erroneous animal husbandry practices, adverse climatic conditions and poor pasture management are responsible for the higher incidence and severity of the parasitic diseases in domestic animals ${ }^{[2]}$. Although most of the helminth infections in domestic animals are asymptomatic but heavy worm load may cause poor growth and digestive disturbances like constipation, diarrhoea and dysentery. Nematodes like Strongyloides spp. are obligate gastrointestinal parasites of vertebrates. Diagnosis of the Strongyloides spp. infections is mainly done by microscopic examination of the host faeces for Strongyloides spp. eggs or the first stage larvae (L1). The eggs of Strongyloides spp. are thin walled, larvated and ellipsoid in shape ${ }^{[3]}$. The main aim of the current study was to evaluate the clinical signs, diagnosis and medicinal management of Strongyloidiasis in Murrah calves.

\section{History and Clinical findings}

Two Murrah calves with an age of 2 months and 3.5 months were reported to Government Veterinary Hospital, Imlota, Charkhi Dadri (Haryana) with a complaint of frothy shooting diarrhoea since 2-3 days. Grossly, faeces of the calves were foamy and watery. Body condition of both the calves was emaciated.

\subsection{Clinical signs and diagnosis}

The body temperatures of the calves were $99.6^{\circ} \mathrm{F}$ and $101.2^{\circ} \mathrm{F}$. Haemoglobin values of the calves were $10.8 \mathrm{~g} / \mathrm{dl}$ and $12.2 \mathrm{~g} / \mathrm{dl}$. Increase in the respiratory rate and heart rate was also observed (Table 1). Diagnosis was based on the microscopic faecal examination under the 10X magnification (Fig. 1) and the 40X magnification (Fig. 2). Microscopic examination revealed the presence of thin walled larvated eggs which were ellipsoid in shape ${ }^{[3]}$. Reference values of the above mentioned parameters were taken from the literature ${ }^{[4]}$.

\section{Deepak}

Corresponding Author:

Veterinary Surgeon, Department

of Animal Husbandry and

Dairying, Haryana, India 
Table 1: Physiological parameters and haemoglobin values of the affected calves

\begin{tabular}{|c|c|c|c|}
\hline Parameter & $\mathbf{1}^{\text {st }}$ calf & $\mathbf{2}^{\text {nd }}$ calf & Normal Values ${ }^{[4]}$ \\
\hline Age & 3.5 months & 2 months & - \\
\hline Temperature $\left({ }^{0} \mathrm{~F}\right)$ & 101.2 & 99.6 & $101-102$ \\
\hline Respiration rate / minute & 31 & 37 & $12-16$ \\
\hline Heart rate / minute & 64 & 68 & $40-60$ \\
\hline Haemoglobin $(\mathrm{g} / \mathrm{dl})$ & 12.2 & 10.8 & $8.5-12.5$ \\
\hline
\end{tabular}

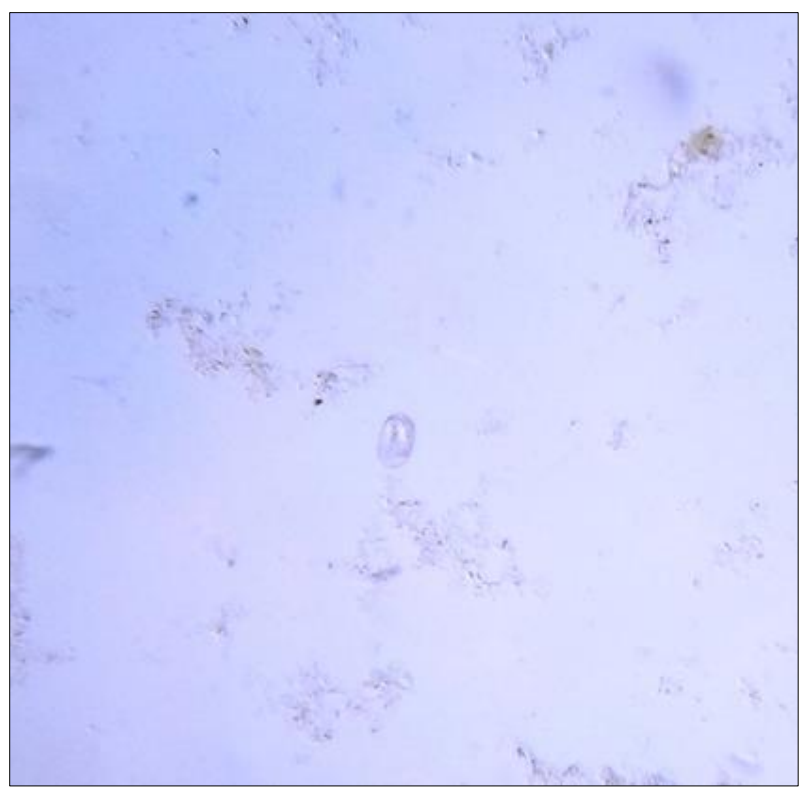

Fig 1: Strongyloides spp. egg seen under 10X magnification

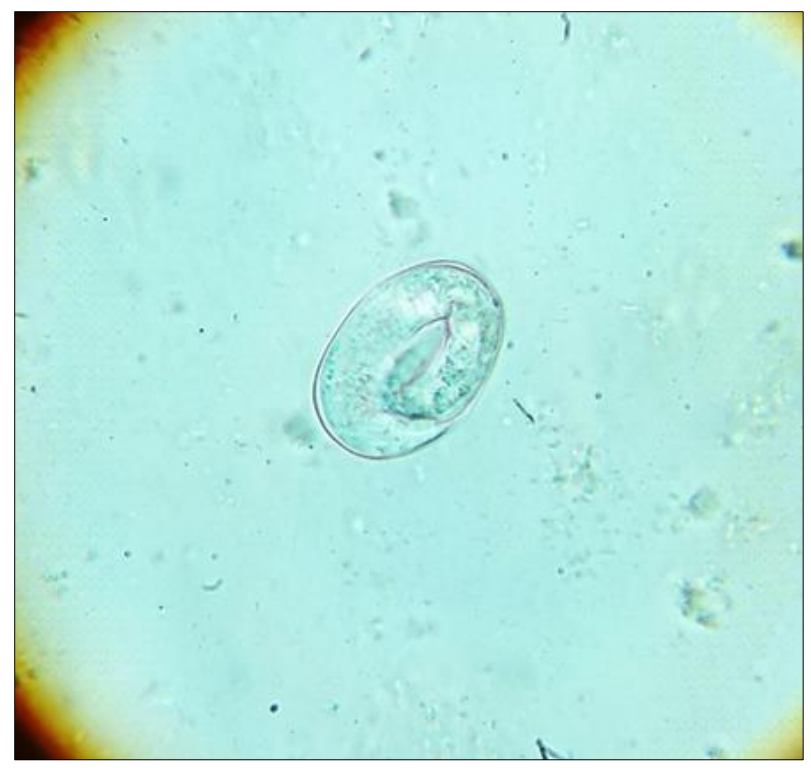

Fig 2: Strongyloides spp. egg (thin walled, larvated and ellipsoid in shape) seen at $40 \mathrm{X}$

\section{Treatment}

Both the calves were treated with Piperazine hexahydrate @ $300 \mathrm{mg} \mathrm{/} \mathrm{kg} \mathrm{body} \mathrm{weight} \mathrm{orally} \mathrm{and} \mathrm{with} \mathrm{Levamisole}$ hydrochloride@7.5 mg / kg body weight subcutaneously. The calves were also given antidiarrheal powder - Neblon ${ }^{\circledR}$ (Indian Herbs) 10 grams twice a day orally for consecutive 3 days as a supportive therapy.

\section{Results and Discussion}

Significant improvement was seen in the affected calves from $3^{\text {rd }}$ day post-treatment. Faeces of both the calves were again examined on $7^{\text {th }}$ day post treatment and were found negative for Strongyloides spp. eggs. Post-therapeutic remission of clinical signs confirmed complete recovery. The affected calves were successfully treated with Piperazine hexahydrate and Levamisole hydrochloride. Aforementioned combination of these broad spectrum anthelmintic drugs is active against a wide range of larval and adult Strongyloides spp. ${ }^{[5]}$.

Strongyloides spp. eggs are larvated and are expelled in the faeces. In the host faeces the eggs hatch to release the L1s. These L1s may develop via L2 - L4 stages into rhabditiform male and female worms which are the free-living adult generation ${ }^{[3]}$. These free-living adults mate and the female lays eggs which hatch to release the L1s which moult via an L2 into infective filariform L3 stage. These infective L3 stages are long lived and can persist in the environment until they encounter a suitable host ${ }^{[3]}$.

The prevalence of Strongyloides papillosus in buffalo calves aging 10 days to 6 months was $28.45 \%$ in Punjab which adjoins Haryana ${ }^{[6]}$. Cases of Strongyloides papillosus infection during the monsoon season (July) in the neonatal calves of up to one month age were also reported in an organised buffalo herd of Haryana ${ }^{[7]}$. Hence, scheduled frequent deworming is advised in the prevalent areas of helminthic infections for enhanced growth and productivity of the animals.

\section{Conclusion}

Strongyloidiasis generally causes minor health problems especially in young ruminants but it significantly affects the growth and productivity of the animals causing remarkable economic losses to the farmers. Combination of Piperazine and Levamisole is a proven broad spectrum anthelmintic combo and its efficacy against Strongyloides spp. is proved by the current study. Regular deworming is advised in the prevalent areas of Strongyloides spp. infections for better productivity of the animals.

\section{References}

1. Raza MA, Iqbal Z, Jabbar A, Yaseen M. Point prevalence of gastrointestinal helminthiasis in ruminants in southern Punjab, Pakistan. Journal of Helminthology. 2007; 81(3):323-328.

2. Marskole P, Verma Y, Dixit AK, Swamy M. Prevalence and burden of gastrointestinal parasites in cattle and buffaloes in Jabalpur, India. Vet. World. 2016; 9:12141217.

3. Viney ME, Lok JB. Strongyloides spp. Worm Book, ed. The C. elegans Research Community, Worm Book, 2007. doi/10.1895/ wormbook.1.141.1

4. Sharma MC, Kumar M, Sharma RD. Textbook of Clinical Veterinary Medicine. 1st edn, ICAR, New Delhi, 2009, 604-609.

5. Samal AK, Patra PB, Maharana BR. Simultaneous Infestation of a Buffalo calf with Ascaris and strogyloides: A case study. Veterinary World. 2011; 4(7):322-323.

6. Jyoti, Singh NK, Juyal PD. Prevalence of gastrointestinal parasites in buffalo calves from different agroclimatic zones of Punjab. Journal of Parasitic Diseases. 2014; 38(4):367-370.

7. Rana N, Manuja A, Saini A. A study on parasitic prevalence in neonatal buffalo calves at an organized herd in Haryana. Haryana Veterinarian. 2011; 50:95-97. 